\title{
Influence of isolation by environment and landscape heterogeneity on genetic structure of wild rice Zizania latifolia along a latitudinal gradient
}

1 Godfrey Kinyori Wagutu ${ }^{1,2,3}$, Xiangrong Fan ${ }^{1,4,5}$, Wenlong Fu ${ }^{1,2}$, Wei Li $^{1}$, Yuanyuan Chen ${ }^{1^{*}}$

$2 \quad{ }^{1}$ Key Laboratory of Aquatic Botany and Watershed Ecology, Wuhan Botanical Garden, Chinese

3 Academy of Sciences, Wuhan, China

$4 \quad{ }^{2}$ University of Chinese Academy of Sciences, Beijing, China

$5 \quad{ }^{3}$ Sino-Africa Joint Research Center, Chinese Academy of Sciences, Wuhan, China

$6 \quad{ }^{4}$ College of Science, Tibet University, Lhasa, Tibet Autonomous Region, China

$7 \quad{ }^{5}$ Research Center for Ecology and Environment of Qinghai-Tibetan Plateau, Tibet University, Lhasa,

8 Tibet Autonomous Region, China

9 * Correspondence:

10 Yuanyuan Chen

11 yychen@wbgcas.cn

12 Keywords: genetic structure, isolation by environment, landscape heterogeneity, latitudinal 13 gradient, microsatellite markers, Zizania latifolia

\section{Abstract}

Global aquatic habitats are undergoing rapid degradation and fragmentation as a result of land-use change and climate change. Understanding the genetic variability and adaptive potential of aquatic plant species is thus important for conservation purposes. In this study, we investigated the role of environment, landscape heterogeneity and geographical distance in shaping the genetic structure of 28 natural populations of Zizania latifolia (Griseb.) Turcz. Ex Stapf in China based on 25 microsatellite markers. Genetic structure was investigated by analysis of molecular variance (AMOVA), estimation of $F_{\mathrm{ST}}$, Bayesian clustering and Thermodynamic Integration (TI) methods. Isolation by environment (IBE), isolation by resistance (IBR) and isolation by distance (IBD) hypotheses were compared using a reciprocal causal model (RCM). Further, generalized linear models and spatially explicit mixed models, by using geographic, landscape and genetic variables, were developed to elucidate the role of environment in driving Z. latifolia genetic diversity. The genetic differentiation across all populations was high: $F_{\mathrm{ST}}=0.579 ; \varnothing_{\mathrm{pt}}=0.578$. RCM exclusively supported IBE in shaping genetic structuring, only partial support for IBR, but not for IBD. Maximum temperature of the warmest month and precipitation seasonality were the plausible parameters responsible for genetic diversity. After controlling for spatial effect and landscape complexity, precipitation seasonality was significantly associated with genetic diversity. Based on these findings, genetic structure of Z. latifolia across China seem to be as a result of local adaptation. Environmental gradient and topographical barriers, rather than geographical isolation, influence genetic differentiation of aquatic species across China resulting in instances of local adaptation. 
Species adaptation to the changing environment mainly depend on the level of standing genetic variation in the populations (Lande and Shannon, 1996; Bell and Collins, 2008). Gene flow patterns, one of the factors influencing genetic variability, are affected by the movement of gametes, individuals and groups of individuals under the influence of landscape features (Sork et al, 1999). This further impacts the spatiotemporal patterns of genetic structure and evolution of natural populations (Slatkin, 1985). Climate and land-use changes are the major drivers of environmental alterations. For instance, global warming has led to temperature and precipitation fluctuations with instances of extreme episodes (Grant et al., 2017; Marrot et al., 2017), which result in plant populations' selective pressure (Hoffmann and Sgrò, 2011; Cao et al., 2015). On the other hand, increase in human population has resulted in rapid conversion of natural lands to farmlands, urban and industrial areas leading to habitat loss and fragmentation (Zhao et al., 2013; Davidson, 2014). The overall effect is decline in population size of native species, which is the initial stage of species local disappearance and eventual extinction (An et al., 2007; Qin, 2008; Halley et al., 2016; Pykälä, 2019). Habitat degradation has profound effects particularly on aquatic plants that live in fragmented islands within the terrestrial landscapes. Additionally, most aquatic plants persist as metapopulations, the long-term survival of which depends on continuous gene flow among populations (Barrett et al., 1993; Santamaría, 2002). Therefore, clear understanding of genetic variability of aquatic plant species occurring across a large spatial scale is important for estimation of the current vigor under the different abiotic and biotic conditions and hence the potential to adapt to the changing environment (Catullo et al., 2019). Knowledge about the major drivers of gene flow is important for the conservation and management of aquatic plants.

The rapid emergence and multidisciplinary nature of landscape genetics has introduced several hypotheses that assess the relationship between spatially explicit landscape variables and genetic measures (Manel and Holderegger, 2013; Hall and Beissinger, 2014). This is in an effort to understand whether dynamic landscape complexities limit gene flow thus resulting in discrete population structure (isolation by barrier, IBR), or clinal population structure is as a result of isolation by distance (IBD) and/or isolation by environment (IBE) (Meirmans, 2012; Landguth and Schwartz, 2014). Clustering of individuals in natural populations could be due to IBD, IBE, IBR or a combination of either (Cushman et al. 2006; Andrews, 2010; Wang and Bradburd, 2014; van Strien et al., 2015). IBD pattern results from geographical isolation, which limits gene flow and promotes genetic drift (Wright, 1943). This model assumes that genetic structure is driven by the linear relationship between geographic distance and genetic distance. It disregards the effects of nonlinear complex landscapes, environmental variables and historical processes that influence gene flow (Jenkins et al., 2010). IBR model considers landscape features and historical processes in explaining the impediment to gene flow (McRae, 2006). Both IBD and IBR are concerned with the limitations to the dispersal of gametes, but fails to accommodate the effects of environmental variables. Moreover, discrete population structure can be misinterpreted as an IBD or IBR pattern, and this may confound identification of environmental contributions resulting in overestimation of population clustering (Tucker et al., 2014). In contrast, IBE considers the contribution of environmental heterogeneity in shaping the distributions of spatial genetic variation independent of geographical isolation (Wang and Bradburd, 2014). Most empirical research on population genetics has focused on gene flow and genetic drift as drivers of genetic structure ignoring environmental-driven natural selection (Orsini et al., 2013). Understanding the environmental variables shaping genetic variation in natural populations is, therefore, important in evolutional studies and thus environmental gradients should be quantified and ecological approach included in population genetics studies (Lee and Mitchell-Olds, 
2011). This information could be crucial in defining conservation and management units for the ecologically and economically important species (Segelbacher et al., 2010; Luque et al., 2012).

The wild rice Zizania latifolia is a perennial aquatic grass, and an important ecological and genetic resource in China. To date, the genetic differentiation of the wild rice across China has been attributed to IBD (Chen et al., 2017; Zhao et al., 2018; 2019). This is despite the fact that the distribution of wetlands in China, which represents the extant natural habitat for the species, has more unique features besides being expansive and patchy. The wetland ecosystem has a regional (Eastern) pattern with swamps distributed in the Northeast region and lakes in the middle-lower reaches of the Yangtze River and the Qinghai Tibet Plateau (Wang et al., 2012). Mangrove wetlands are distributed in the southeast coastal area. Topographically, the Eastern region, where most of the wetlands are found, is characterized by three plains; North, Northeast and Middle-Lower Yangtze plains amongst which foothills and hills are interspersed. This is the most economically important region characterized by a dense population, agriculture, and industries (An et al., 2007). China natural wetlands characteristics and distribution of $Z$. latifolia, therefore, presents an opportunity to study the landscape genetics of widespread species that have for long been neglected by conservation genetics community (Morente-López et al., 2018). This would aid in delineating the impact of islandlike aquatic species distribution as well as human- and climate-change-induced habitat degradation (An et al., 2007) on the genetic structure of riparian plants at different spatial and environmental gradients. Further, the environmental gradient provides a perfect model for space-for-time substitution in assessing the long term aquatic ecosystem response to the changing environment (De Frenne et al., 2011).

In this study, we aimed to study the genetic diversity and population structure of 28 natural population of Z. latifolia based on 25 simple sequence repeat (SSR) markers and determine the influence of IBD, IBR and IBE in shaping the genetic structure. Based on the patchy nature of the wild rice habitat and the extensive latitudinal geographic range of the studied populations, it was predicted that $Z$. latifolia would show strong spatial genetic structure driven by diverse biotic and abiotic factors. It was expected that population decline and discontinuity, due to habitat degradation and fragmentation (An et al., 2007), could have considerable influence on wild rice reproduction system and gene flow, resulting in low genetic diversity. Further, we hypothesized that Z. latifolia genetic structure, in the expansive range and heterogeneous landscape, could be explained by combined effects of geographic isolation (IBD), gene-flow-limiting landscape variables (IBR) and differences in environmental variables between populations (IBE).

\section{MATERIALS AND METHODS}

\subsection{Focal species, sampling and SSR data}

The wild rice Zizania latifolia, commonly known as the Chinese wild rice, belongs to the family Poaceae, tribe Oryzeae. It shares the genus Zizania L. with other three species distributed in North America (Z. aquatic Z. palustris and Z. texana) (Xu et al., 2010). Z. latifolia is a perennial species distributed in Eastern Asia and well differentiated from the North American species (Brown, 1950; Dore, 1969; Chen et al., 1990; Kennard et al., 2000). It grows along the margins of lakes and rivers, ponds and marshes, and reproduces sexually by seeds or asexually by rhizomes (Xu and Zhou, 2017). In China, the wild rice is an important ecological species that is exploited for wastewater purification due to its high nutrient uptake capacity (Liu et al., 2007; Zhou et al., 2007; Peng et al., 2013) and high clonal reproduction (Chen et al., 2017). It also carries important genetic traits that include disease and pest resistance, elite grain, and tolerance to cold and flooding (Liu et al., 1999; Yu et al., 2006; Shen et al., 2011; Wang et al., 2013). Natural populations of Z. latifolia are 
distributed along the East of China along a wide stretch of latitudinal zones $\left(21^{\circ} \mathrm{N}-50^{\circ} \mathrm{N}\right)$ (Wagutu et al., 2020). This region has five major eco-geographic regions that vary in biotic and abiotic factors that influence gene flow and local adaptation (Wu et al., 2003).

Twenty-eight populations of $Z$. latifolia were collected across China from Heilongjiang province to Guangdong province (Table 1) in a cluster sampling approach (Li et al., 2017). This was based on the size of the population, which should be large enough to allow a random selection of at least 20-23 samples at intervals of 10 meters. Samples were collected in the natural wetlands; rivers, lake shores and marshes during early autumn as the wild rice approaches maturity. GPS coordinates were recorded at the center of each collection transect and mapped using ArcGIS (Figure 1). The two uppermost leaves from each selected individuals were harvested, individually dried in silica gel and stored in the laboratory for DNA extraction. Total genomic DNA was extracted from $0.5 \mathrm{~g}$ dried leaves using a modified CTAB protocol (Doyle and Doyle, 1987). Twenty five SSR markers were used in this study, including 20 markers developed for Z. latifolia (Quan et al., 2008; Wagutu et al., 2020), three SSR markers for Oryza sativa (Wang et al., 2015) and two markers developed for $Z$. texana (Richards et al., 2007) (Supplementary Table S1). PCR amplification was performed following the protocol by Quan et al. (2008) and PCR products separated on a 6\% denaturing polyacrylamide gel. Fragments were visualized by silver staining and alleles scored in reference to a 25bp DNA ladder (Promega, Madison, WI, USA).

GenoDive 2.0 (Meirmans et al., 2004) was used to identify clonal structure. At threshold zero, samples were assigned to their respective clones. The number of genotypes $(G)$ was calculated and repeating genotypes excluded from further analysis. Micro-Checker 2.2.3 (Van Oosterhout et al., 2004) was used to test for null alleles and genotyping errors. Genetic diversity across all loci for every population and for each locus was estimated in terms of observed allele number $\left(N_{\mathrm{a}}\right)$, the effective number of alleles $\left(N_{\mathrm{e}}\right)$, and expected and observed heterozygosity $\left(H_{\mathrm{E}}\right.$ and $\left.H_{\mathrm{O}}\right)$ using GenAlEx software (Peakall and Smouse, 2012). FSTAT (Goudet, 2001) was used to calculate the inbreeding coefficient $\left(F_{\mathrm{IS}}\right)$, deviation from Hardy-Weinberg equilibrium and linkage disequilibrium.

\subsection{Genetic structure among populations}

FSTAT software was used to measure population genetic divergence by estimation of $F_{\text {ST }}$ using 999 permutations for their significance. Based on $F_{\text {ST }}$ values, an average level of gene flow $(N m)$ was estimated using the formula: $\left[N m=\left(1-F_{\mathrm{ST}}\right) / 4 F_{\mathrm{ST}}\right]$ (Slatkin and Barton, 1989). ARLEQUIN software (Schneider et al., 2000) was used to perform analysis of molecular variance (AMOVA) to determine genetic variation among and within populations. STRUCTURE program (Pritchard et al., 2000) was used to perform Bayesian clustering of the samples. Ten independent runs for each number of $K$ clusters from one to ten was performed. A 20,000 iteration burn-in period followed by 100,000 Markov Chain Monte Carlo (MCMC) iterations were assumed for each run with correlated allele frequencies and admixture origin assumptions. To determine the value of $K$, the output was interpreted with Structure Harvester (Evanno et al., 2005; Earl and vonHoldt, 2012). However, Evanno's delta $K$ method has been reported to suffer philosophical and statistical errors (Verity and Nichols, 2016). Therefore, it was supplemented with Thermodynamic Integration (TI) method (Verity and Nichols, 2016). Here, rmaverick R package was used to estimate the true value of $K$ by running 20 rungs for $K=1$ to 10 with a burn-in period of 10,000 iterations followed by 50,000 MCMC iterations under the admixture model. The value of $K$ was estimated as described by Verity and Nichols (2016). Since both software did not differ in the estimation of $K$, Structure Harvester output was visualized by DISTRUCT v. 1.1 (Rosenberg, 2004). Identified clusters were analyzed for 
molecular variations (AMOVA) using ARLEQUIN software. Geographical distribution of the different clusters identified was mapped using ArcGIS 10.0 (Esri, Redlands, CA, USA).

\subsection{Geographic and environmental influence on the genetic structure}

To determine the drivers of the observed genetic structure in Z. latifolia, we tested for isolation by distance (IBD), isolation by resistance (IBR) and isolation by environment (IBE) hypotheses. Four matrices were obtained in order to explore the three assumptions. Genetic distance was calculated as pairwise $F_{\text {ST }}$ using FSTAT software, while the geographic distance matrix was based on Euclidean distance between populations calculated using GenAlEx. To linearize genetic and geographic distances relationship, both matrices were transformed: $\left[F_{\mathrm{ST}} /\left(1-F_{\mathrm{ST}}\right)\right]$ and $\log ($ Euclidean distance), respectively (Rousset, 1997). Nineteen environmental variables were extracted for the studied sites from BioClim's 30s resolution dataset (Busby, 1991) with GIS details using ArcGIS software (Supplementary Table S2). PAST ver. 3.24 (Hammer et al., 2001) was used to reduce climatic variables by principal component analysis (PCA) based on 20 variables (19 bioclimatic variables and elevation). The first principle components (PC) was used as it represented $99.32 \%$ of the variation in the data. Environmental distance matrix was calculated using the first principal component using vegan package in $\mathrm{R}$ (Oksanen et al., 2018). Lastly, resistance distance was calculated as the conductance matrix on a 30 -arc seconds resolution digital elevation model (DEM) (Danielson and Gesch, 2011) of the study site using gdistance package implemented in R (van Etten, 2017). The resistance distance was obtained by calculating the effective resistance between populations when the DEM grid is conceived as an electrical circuit (McRae et al., 2008). Since wind dispersal is considered a major factor in Zizania latifolia gene flow, DEM was slope-modeled in ArcGIS 10.0. The grid cells with high values (high slope) contribute high resistance to gene flow and those with low value contribute the least resistance. Movement from any cell within the grid followed the standard eight directions (McRae et al., 2008).

To compete the three hypotheses, we used reciprocal causal modeling (RCM) (Cushman et al., 2006; 2013b) that eliminates the simple Mantel test's (Mantel, 1967) limitations of spurious correlations and type I error (Cushman and Landguth, 2010). The RCM method directly compares the different hypotheses and identifies whether any of them is relatively supported independently of the other alternatives. The approach is based on a pair of partial Mantel tests derived from two models at a time. First, partial Mantel was performed between genetic distance (Gen) and IBD, partialling out IBR (Gen IBD $\mid$ IBR). The second partial Mantel was performed between the genetic distance (Gen) and IBR, partialling out the IBD (Gen IBR|IBD). The difference between the two partial Mantel tests (IBD|IBR- IBR|IBD) was the relative support for IBD relative to IBR (Cushman et al., 2013a). In that case, the difference between the partial mantel should be positive if IBD is correct, and zero or negative if the IBR is correct. The full matrix of the partial Mantel tests differences between pairs of alternative hypotheses was computed. A hypotheses was regarded as fully supported, independent of all alternatives, if all the values in its column were positive and the values in the row were negative (Cushman et al., 2013a, b). Correlation values and significance values for the Mantel model combinations were calculated through 9999 corrected permutations using vegan $\mathrm{R}$ package.

We further evaluated the relationship between genetic diversity estimators and geographic and environmental variables through generalized linear models (GLMs) using PAST ver. 3.24 (Hammer et al., 2001) and spatially explicit mixed modeling (Morente-López et al., 2018) using spaMM R package (Rousset and Ferdy, 2014). Firstly, generalized linear models were used to explore the contribution of each environmental variable to genetic diversity estimators $\left(H_{\mathrm{O}}, H_{\mathrm{E}}\right.$ and $N_{\text {a)}}$. Secondly, spatially explicit generalized linear mixed models (spatial GLMMs) were developed using genetic, geographic (coordinates and elevation) and environmental data. Here, we used genetic 
217 diversity estimators $\left(H_{\mathrm{O}}, H_{\mathrm{E}}\right.$ and $\left.N_{\mathrm{a}}\right)$ as response variables, each of the 19 environmental variables as

218 fixed effects and geographical coordinates and elevation as random effects. We transformed

219 environmental variables as required, including using their squared values to account for non-linearity. Full models (e.g. $\left[F_{\text {IS }} \sim\right.$ bio $1+(1 \mid$ lat+long/Elevation) $\left.]\right)$ and null models (e.g. $\left[F_{\text {IS }} \sim 1+\right.$

221 (1|lat+long/Elevation)]) were tested for associated likelihood ratio to obtain the $P$-value.

\section{RESULTS}

From 578 individuals, 570 multilocus genotypes were identified, and no genotype was shared

\subsection{Genetic structure and differentiation among populations}

The genetic differentiation across all populations based on $F_{\mathrm{ST}}$ was 0.579 (Table 2). Pairwise comparisons of $F_{\mathrm{ST}}$ were significant for genetic differentiation between populations $(P=0.01)$.

237

238 Moreover, the levels of differentiation were high; $F_{\mathrm{ST}}=0.103$ to 0.823 (Supplementary Table S3). AMOVA showed high population differentiation at $\varnothing_{\mathrm{pt}}=0.578(P=0.000)$. Variation among populations was $58 \%$, while $42 \%$ of the variation was within population, both statistically significant $(P=0.001)$ (Table 3). Bayesian clustering using structure identified optimum $K=5$ using the Evanno's delta $K$ as well as TI method (Pritchard et al., 2000; Verity and Nichols, 2016). Populations from the five regions clustered according to their respective collection sites (Figure 2). Membership proportion of predefined populations in each of the 5 clusters ranged from 0.857 to 0.997 . AMOVA showed that $36 \%$ of variation was among clusters (Table 3 ). The five identified clusters were mapped using ArcGIS (Figure 1).

\subsection{Geographic and environmental influence on the genetic structure}

IBE model was fully supported based on the relative support values of the reciprocal causal model. The column had positive values and the row had negative values (Table 4) indicating that it explained the genetic structure independent of the alternative hypotheses. Moreover, the partial Mantel tests between genetic distance and environmental distance controlling for both resistance and geopgraphy showed significant positive correlations (Table 4). IBR model had one positive value in the column when competed with IBD and partial Mantel tests were all significant. IBD model had all negative value in the column and thus had the least relative support. However, partial Mantel tests when controlling for IBR showed a significant positive correlation. In simple Mantel, environmental distance had the highest significant positive correlation with genetic distance followed by resistance distance and then geographical distance (Table 4).

Generalized linear models showed that seven of the 19 bioclimatic variables had significant contribution to genetic diversity of Z. latifolia (Table 5). However, spatially explicit mixed models 
with coordinates as random effect showed no significant influence of environmental variables to genetic diversity. When elevation was used as the random effect in the mixed models, bio_15 showed significant influence $(P=0.038)$ on number of alleles $\left(N_{\mathrm{a}}\right)$. We tested the seven environmental variables showing significant contribution to genetic diversity in GLM for collinearity using variance inflation factor (VIF) analysis (Helsen et al., 2017). Two variables; bio_ 5 and bio_15 had VIF value below 2 and were therefore identified as the best environmental variables responsible for the genetic diversity of $Z$. latifolia.

\section{DISCUSSION}

In this study, Zizania latifolia showed relatively low genetic diversity $\left(H_{\mathrm{E}}=0.292\right)$. A similar level of genetic diversity was reported in its natural populations from the Northeast wetland $\left(H_{\mathrm{E}}=\right.$ 0.328; Chen et al., 2017) and the lower-middle Yangtze wetland ( $H_{\mathrm{E}}=0.271$; Wang et al., 2015) using SSR markers. Our results are consistent with the expected average genetic variability for the family Poaceae $\left(H_{\mathrm{E}}=0.201\right)$, which is estimated based on characteristics that influence gene flow (Hamrick and Godt, 1996). These results also correspond to Northern American wild rice Z. palustris genetic diversity $\left(H_{\mathrm{E}}=0.236\right.$; Lu et al., 2005). Further, $Z$. latifolia shows lower genetic diversity compared to $Z$. texana $\left(H_{\mathrm{E}}=0.662\right.$; Richards et al., 2007). However, the two studies employed different sampling approaches, with Richards et al. (2007) considering a single hydrologically connected river system, while we sampled different populations across large geographical and environmental gradient (Figure 1). A higher than average genetic diversity in populations in region III, along the Yangtze River $\left(H_{\mathrm{E}}=0.424\right)$ and region IV, along the Yellow River $\left(H_{\mathrm{E}}=0.426\right)$ was observed. Similar results were reported by Chen et al. (2012) and Zhao et al. (2018) who showed that Z. latifolia wild populations in the middle and lower reaches of the Yangtze basin exhibit high genetic diversity. This could be explained that, the central and southeast China wetlands are characterized by episodic floods that create temporary hydrological connectivity (Wang et al., 2008) resulting in gamete exchange between population. Genetic diversity is then maintained by the high clonal capacity of the species.

\subsection{Genetic structure and differentiation among populations}

High level of genetic differentiation among populations was detected $\left(F_{\mathrm{ST}}=0.579 D_{\text {est }}=\right.$ 0.598). Our results are comparable to $Z$. latifolia genetic differentiation reported recently $\left(F_{\mathrm{ST}}=\right.$ 0.481, $\mathrm{Xu}$ et al., 2008; $F_{\mathrm{ST}}=0.405$, Chen et al., 2017). AMOVA analysis also showed high population differentiation at $\emptyset_{\mathrm{pt}}=0.578(P=0.001)$, with $58 \%$ variation attributed to between populations and $42 \%$ to within population $(P=0.001)$ variation. This was also comparable to $Z$. latifolia population differentiation $\left(\varnothing_{\mathrm{pt}}=0.598\right)$ reported by Xu et al. (2015). Moreover, high population differentiation was also reported in the North American relatives of Z. latifolia ( $Z$. aquatica: $F_{\mathrm{ST}}=0.607 ; Z$. palustris: $F_{\mathrm{ST}}=0.468 ; \mathrm{Xu}$ et al., 2015). The observed high genetic divergence is attributable to decreased gene flow between populations $(\mathrm{Nm}=0.061)$. According to Wright (1969), when $\mathrm{Nm}$ is perceived as the exchange of migrants between demes per generation, a value $>1$ result in little divergence, while value $<1$ results in increased divergence. In our case, conventional fragmentation of wetlands into islands within the expansive terrestrial habitat and induced fragmentation could explain the negligible gene flow and the observed high genetic differentiation (Wagutu et al., 2020). Moreover, inbreeding system detected in some populations could have contributed to the high genetic differentiation. Bayesian clustering using STRUCTURE software and rmaverick (R package) identified five clusters (Figure 2). All the five clusters corresponded to the wetland from which the samples were collected. The clustering pattern can be attributed to the $Z$. latifolia habitat, which is discrete and patchy within an expansive geographical 
range (Zhao et al., 2018). Further, dispersal of its gametes and somatic propagules depend on hydrological connectivity and landscape features. In such spatially isolated populations under a heterogenous landscape, wind and water dispersal is most effective locally creating locally identical genotypes. Environmental difference between the geographically isolated populations promote phenotypic plasticity and genetic changes.

\subsection{Environmental, landscape and geographical influence on genetic structure and genetic diversity}

For the first time, this study tested for IBE and IBR patterns, besides the commonly tested IBD pattern in the natural populations of $Z$. latifolia. Interestingly, we found exclusive relative support by RCM for IBE pattern, partial support for IBR, but not IBD, in shaping genetic structuring of the species. Similarly, Šurinová et al. (2019) reported that environmental variables, but not geographical distance, explained genetic relatedness among a perennial grass species (Festuca rubra) populations. Wu et al. (2019), when comparing IBD and IBE in aquatic species Ranunculus subrigidus on the Qinghai-Tibetan plateau, also found exclusive support for environmental isolation. Further, IBE has been reported as a more common phenomenon compared to IBD in a wide range of taxa (Shafer et al., 2013; Sexton et al., 2014), although it has for long been neglected in population genetic studies. IBE can be generated by various ecological processes that include; natural and sexual selection against maladapted immigrants, poor hybrid fitness and biased dispersal (Wang and Bradburd, 2014). In natural selection, populations evolve traits suitable for the environment and thus acquire higher fitness compared to immigrants from different environments. Sexual selection and dispersal bias may occur as a result of phenotypic plasticity. Here, environmental conditions influence reproductive physiology affecting synchronization of mating and dispersal processes such flowering and gamete release. Moreover, if immigrates survive long enough and are able to mate locally, hybrids would undergo selection against immigrant alleles (Sexton et al., 2014). The sexual reproduction of $Z$. latifolia could be one characteristic that makes natural and sexual selection as well as dispersal bias drive local adaptation and thus the observed pattern of IBE. However, the species also reproduces asexually through rhizomes and thus hybrids survival could be a tradeoff. The net effect of ecological processes targeting sexual reproduction and asexual reproduction, however, seems to favor local adaptation and hence the exclusive support of IBE by RCM.

In this study, IBE was further supported by the significant relationship between genetic diversity estimators and a number of environmental variables in the GLMs, although limited relationship in the spatial GLMMs (Table 5). Maximum temperature of the warmest month (bio_5) and precipitation seasonality (bio_15) were identified as the best environmental variables responsible for observed genetic differentiation based on VIF analysis. Temperature and precipitation are major drivers of plant adaptability through their influence on physiology and diversity (Hoffmann and Sgrò, 2011; Manel et al., 2012), forcing genetic change events and subsequent selection. Besides our study, influence of temperature and precipitation on genetic differentiation of both aquatic and terrestrial plants have been reported (Wang et al., 2016; Münzbergová et al., 2017). A significant relationship between precipitation seasonality (bio_15) and $N_{\text {a }}$ was detected in our study. This indicates that the local adaptation, driven by interaction between precipitation and temperature, is responsible for $Z$. latifolia differentiation along the eastern China aquatic ecosystem. This could be due to the fact that the species is tolerant to a wide range of temperatures (Guo et al., 2007), but since it's an aquatic species, the differences in precipitation along the sampling sites and between seasons has profound influence. As a perennial and aquatic species, Z. latifolia reproduction and growth will be affected by temperature and precipitation fluctuations. Flowering, vegetative growth and reproductive success of plants have been reported to respond to temperature changes (De FRENNE et al., 2011). Similarly, 
asynchronous flowering due to heterogenous rainfall patterns have been associated with IBE pattern (Garot et al., 2019).

IBR was the second best model explaining Z. latifolia genetic structuring. In partial Mantel, IBR had a positive correlation with genetic diversity when controlling for both geographical distance and environment. The model was partially supported by RCM (Table 4). Similarly, significant effect of cost distance on genetic differentiation has been reported in alpine ecosystem (Morente-López et al., 2018). Wetlands along eastern China are islands within terrestrial ecosystem interspersed with foothills and hills (An et al., 2007; Santamaria, 2002). Such natural barriers are important factors in the gene flow of flowering plants. Similar, albeit artificial barriers, have been reported to drive genetic differentiation in species that depend on wind, insects and birds for pollination and seed dispersal (Su et al., 2003). In the case of Z. latifolia, wind pollination seems to be inhibited by the complex landscape along the eastern China, and seed dispersal by lack of hydrological connectivity, which leads to genetic drift and thus population differentiation.

The exclusive IBE pattern detected contradicts Zhao et al. $(2018 ; 2019)$ who reported a

\subsection{Implications for conservation and management}

The genetic variation in the extant natural populations of $Z$. latifolia is relatively low and the pattern of IBD along the eastern China populations of $Z$. latifolia. However, in their study, only IBD was tested using simple Mantel, for which we also found a strong positive correlation $(r=0.5830$; $P=0.001$ ). The observed direct correlation of genetic differentiation with geographical distance between populations could be due to the discrete pattern of $Z$. latifolia populations along the expansive geographical area. Moreover, rapid fragmentation and reclamation of the wetlands (An et al., 2007; Zhao et al., 2018) has increased population isolation, which inhibits wind- and watermediated gamete dispersal. In our study, IBD was the least supported hypothesis in partial Mantel. When controlling for IBR, significant correlation between IBD and genetic differentiation was detected (Table 4). This could be because calculation of cost distance on DEM has an aspect of distance (Morente-López et al., 2018). high genetic divergence is shaped by environmental variation between groups of populations. The heterogenous landscape, discrete distribution of the natural populations coupled with wetland fragmentation and degradation has increased the isolation resulting in genetic isolation. Genetic diversity measures were sensitive to temperature and precipitation. Between 1956 and 2005, earth surface temperature has increased at an average of $0.65^{\circ} \mathrm{C}$ and might increase with further $1.8^{\circ} \mathrm{C}$ to $4^{\circ} \mathrm{C}$ by 2099 (IPCC, 2007). This is expected to affect the precipitation and together impact on species diversity and survival. Therefore, further extensive genetic and morphological studies need to be carried out to identify the role of the environment in shaping local adaptation of the Z. latifolia, besides the aquatic ecosystem response assessment. The use of a common garden approach in combination with genome-wide association studies (GWAS) could help elucidate patterns of local adaptation (de Villemereuil et al., 2016).

Our results show that gene flow is critically inhibited among the populations. Therefore, management and conservation approaches should include both in-situ and ex-situ considerations. Populations in the central and southeast China wetland (e.g. CH, LZX, and DT) that showed the highest genetic variability should be prioritized for germplasm collection and conservation. The genetic profiles of the sampled populations within each of the five clusters could constitute valuable traits that require conservation as well. Geographic barriers showed positive correlation to genetic structuring of Z. latifolia. This is related to topographical complexity, which impedes pollen 
dispersal. While nothing can be done about the topography, seed and somatic propagule dispersal through water can be enhanced. Where landscapes are disconnected, revegetation with broad genotypes can be used to promote gene flow, which may also include deliberate movement of propagules across fragmented landscapes (Reviewed by Sexton et al., 2014). Chen et al. (2017) proposed dredging the watercourses to achieve hydrological connectivity within each wetland. Populations along the Yangtze and Yellow river exchange gametes through periodical floods, which shows that this approach is feasible in other wetlands.

\section{Data accessibility}

All datasets for this study are included in the article's Supplementary Material

\section{Authors' contribution}

$\mathrm{YC}$ conceived the idea and designed the research project. WL gave suggestions to the design of the study. YC, XF and WF collected the samples and assembled experiment materials. GKW, XF performed the experiment. GKW analyzed the data and wrote the manuscript. All authors contributed to the revision and final editing of the manuscript prior to submission.

\section{$7 \quad$ Funding}

411

This work was supported by Chinese Academy of Sciences (Y855291B01) and the CAS-TWAS

\section{$414 \mathbf{8} \quad$ Supplementary material}

415 Supplementary Table S1. Details of SSR primer sequences used in this study

416 Supplementary Table S2. Genetic diversity measures, geographical variables and bioclimatic 417 variables used in in this study

418 Supplementary Table S3. $F_{\text {ST }}$ pairwise matrix, all significant at $P=0.05$

\section{References}

420 An, S., Li, H., Guan, B., Zhou, C., Wang, Z., Deng, Z., et al. (2007). China's natural wetlands: Past 421 problems, current status, and future challenges. AMBIO: A Journal of the Human Environment 422 36(4), 335-342. https://doi.org/10.1579/0044-7447(2007)36[335:CNWPPC]2.0.CO;2

423 Andrews, C. A. (2010). Natural selection, genetic drift, and gene flow do not act in isolation in 424 natural populations. Nature Education Knowledge 3(10), 5.

425 Barrett, S. C. H., Eckert, C. G., and Husband, B. C. (1993). Evolutionary processes in aquatic plant 426 populations. Aquatic Botany 44(2-3), 105-145. https://doi.org/10.1016/0304-3770(93)90068-8

427 Bell, G., and Collins, S. (2008). Adaptation, extinction and global change. Evolutionary

428 applications $1(1), 3-16$. https://doi.org/10.1111/j.1752-4571.2007.00011.x 
431 Busby, J. (1991). BIOCLIM - A bioclimate analysis and prediction system. Plant Protection 432 Quarterly 6, 8-9.

433 Catullo, R. A., Llewelyn, J., Phillips, B. L., and Moritz, C. C. (2019). The Potential for Rapid 434 Evolution under Anthropogenic Climate Change. Current Biology 29(19), R996-R1007.

435 https://doi.org/10.1016/j.cub.2019.08.028

436 Cao, Y., Neif, É., Li, W., Coppens, J., Filiz, N., Lauridsen, T., et al. (2015). Heat wave effects on biomass and vegetative growth of macrophytes after long-term adaptation to different temperatures: A mesocosm study. Climate Research 66(3), 265-274. https://doi.org/10.3354/cr01352

439 Chen, S. L., Qin, H. Z., Jin, Y. X., and Shu, P. (1990). Preliminary studies on systematic position and evolution of Zizania L. (Gramineae). In: Proc. Intern. Symp. Bot. Gard. Nanjing pp. 593-605.

441 Chen, Y.-Y., Chu, H.-J., Liu, H., and Liu, Y.-L. (2012). Abundant genetic diversity of the wild rice 201. https://doi.org/10.1111/j.1744-7348.2012.00564.x 486-499. https://doi.org/10.1086/506976

452 Cushman, S. A., Shirk, A. J., and Landguth, E. L. (2013a). Landscape genetics and limiting factors. Conservation Genetics 14(2), 263-274. https://doi.org/10.1007/s10592-012-0396-0

454 Cushman, S., Wasserman, T., Landguth, E., and Shirk, A. (2013b). Re-Evaluating Causal Modeling 455 with Mantel Tests in Landscape Genetics. Diversity 5(1), 51-72. https://doi.org/10.3390/d5010051

456 Danielson, J. J. and Gesch, D. B. (2011). Global multi-resolution terrain elevation data 2010 457 (GMTED2010): U.S. Geological Survey Open-File Report 26, 2011-1073. 
465 de Villemereuil, P., Gaggiotti, O. E., Mouterde, M., and Till-Bottraud, I. (2016). Common garden https://doi.org/10.1038/hdy.2015.93

468 Dore, W.G. (1969). Wild rice. Can. Dept. Agric. Publ. no. 1393, Ottawa, Ontario, Canada.

469

470

471

472

473

474

475

476

477

478

479

480

481

482

483

484

485

486

487

488

Doyle, J. J., and Doyle, J. L. (1987). A rapid DNA isolation procedure for small quantities of fresh leaf tissue. Phytochem. Bull. 19, 11-15.

Earl, D. A., and vonHoldt, B. M. (2012). STRUCTURE HARVESTER: A website and program for visualizing STRUCTURE output and implementing the Evanno method. Conservation Genetics Resources 4(2), 359-361. https://doi.org/10.1007/s12686-011-9548-7

Evanno, G., Regnaut, S., and Goudet, J. (2005). Detecting the number of clusters of individuals using the software structure: A simulation study. Molecular Ecology 14(8), 2611-2620.

https://doi.org/10.1111/j.1365-294X.2005.02553.x

Garnier-Géré, P., and Chikhi, L. (2013). Population Subdivision, Hardy-Weinberg Equilibrium and the Wahlund Effect. In John Wiley \& Sons Ltd (Ed.), ELS (p. a0005446.pub3). John Wiley \& Sons, Ltd. https://doi.org/10.1002/9780470015902.a0005446.pub3

Garot, E., Joët, T., Combes, M.-C., and Lashermes, P. (2019). Genetic diversity and population divergences of an indigenous tree (Coffea mauritiana) in Reunion Island: Role of climatic and geographical factors. Heredity 122(6), 833-847. https://doi.org/10.1038/s41437-018-0168-9

Goudet, J. (2001). FSTAT ver 2.9.3, A program to Estimate and Test Gene Diversities and Fixation Indices. Available online at: https://www2.unil.ch/popgen/softwares/fstat.htm

Grant, P. R., Grant, B. R., Huey, R. B., Johnson, M., Knoll, A. H., and Schmitt, J. (2017). Evolution caused by extreme events. Philosophical transactions of the Royal Society of London. Series B, Biological sciences 372(1723), 20160146. https://doi.org/10.1098/rstb.2016.0146

Guo, H. B., Li, S. M., Peng, J., and Ke, W. D. (2007). Zizania latifolia Turcz. Cultivated in China. Genetic Resources and Crop Evolution 54(6), 1211-1217. https://doi.org/10.1007/s10722-006-9102$\underline{8}$

Hall, L. A., and Beissinger, S. R. (2014). A practical toolbox for design and analysis of landscape genetics studies. Landscape Ecology 29(9), 1487-1504. https://doi.org/10.1007/s10980-014-0082-3

Halley, J. M., Monokrousos, N., Mazaris, A. D., Newmark, W. D., and Vokou, D. (2016). Dynamics of extinction debt across five taxonomic groups. Nature Communications 7(1), 12283. https://doi.org/10.1038/ncomms12283

Hammer, Ø., Harper, D. A. T., and Ryan, P. D. (2001). PAST: paleontological statistics software package for education and data analysis. Palaeontologia Electronica 4, $1-9$. 
Hamrick, J. L., and Godt, M. J. W. (1996). Effects of life history traits on genetic diversity in plant species. Philosophical Transactions of the Royal Society of London. Series B, Biological Sciences

500 351, 1291-1298.

501 Helsen, K., Acharya, K. P., Brunet, J., Cousins, S. A. O., Decocq, G., Hermy, M., et al. (2017).

502 Biotic and abiotic drivers of intraspecific trait variation within plant populations of three herbaceous

503 plant species along a latitudinal gradient. BMC Ecology 17(1), 38. https://doi.org/10.1186/s12898-

$504 \quad \underline{017-0151-y}$

505 Hoffmann, A. A., and Sgrò, C. M. (2011). Climate change and evolutionary adaptation. Nature

506 470(7335), 479-485. https://doi.org/10.1038/nature09670

507 IPCC (2007). Climate Change 2007: Synthesis Report. Contribution of Working Groups I, II and III

508 to the Fourth Assessment Report. Intergovernmental Panel on Climate Change, Geneva, Switzerland.

509 Jenkins, D. G., Carey, M., Czerniewska, J., Fletcher, J., Hether, T., Jones, A., et al. (2010). A meta510 analysis of isolation by distance: Relic or reference standard for landscape genetics? Ecography 33,

511 315-320. https://doi.org/10.1111/j.1600-0587.2010.06285.x

512 Kennard, W. C., Phillips, R. L., Porter, R. A., and Grombacher, A. W. (2000). A comparative map of

513 wild rice (Zizania palustris L. 2n=2x=30). Theoretical and Applied Genetics 101(5-6), 677-684.

514 https://doi.org/10.1007/s001220051530

515 Lande, R., and Shannon, S. (1996). The role of genetic variation in adaptation and population

516 persistence in a changing environment. Evolution 50, 434-437.

517 Landguth, E. L., and Schwartz, M. K. (2014). Evaluating sample allocation and effort in detecting 518 population differentiation for discrete and continuously distributed individuals. Conservation

519 Genetics 15(4), 981-992. https://doi.org/10.1007/s10592-014-0593-0

520 Lee, C.-R., and Mitchell-Olds, T. (2011). Quantifying effects of environmental and geographical

521 factors on patterns of genetic differentiation. Molecular Ecology 20(22), 4631-4642.

522 https://doi.org/10.1111/j.1365-294X.2011.05310.x

523 Li, Y., Zhang, X.-X., Mao, R.-L., Yang, J., Miao, C.-Y., Li, Z., et al. (2017). Ten Years of Landscape 524 Genomics: Challenges and Opportunities. Frontiers in Plant Science 8, 2136.

525 https://doi.org/10.3389/fpls.2017.02136

526 Liu, B., Piao, H., Zhao, F., Zhao, J., and Zhao, R. (1999). Production and molecular characterization 527 of rice lines with introgressed traits form a wild species Zizania latifolia (Griseb.). J. Genet. Breed.

$52853,279-284$.

529 Liu, J. G., Dong, Y., Xu, H., Wang, D. K., and Xu, J. K. (2007). Accumulation of Cd, Pb and Zn by 53019 wetland plant species in constructed wetland. Journal of Hazardous Materials 147(3), 947-953.

531 doi: 10.1016/j.jhazmat.2007.01.125 
532 Lu, Y., Waller, D. M., and David, P. (2005). Genetic variability is correlated with population size and 533 reproduction in American wild-rice (Zizania palustris var. Palustris, Poaceae) populations. American

534 Journal of Botany 92(6), 990-997. https://doi.org/10.3732/ajb.92.6.990

535 Luque, S., Saura, S., and Fortin, M.-J. (2012). Landscape connectivity analysis for conservation:

536 Insights from combining new methods with ecological and genetic data. Landscape Ecology 27(2),

537 153-157. https://doi.org/10.1007/s10980-011-9700-5

538 Manel, S., and Holderegger, R. (2013). Ten years of landscape genetics. Trends in Ecology \&

539 Evolution 28(10), 614-621. https://doi.org/10.1016/j.tree.2013.05.012

540 Manel, S., Gugerli, F., Thuiller, W., Alvarez, N., Legendre, P., Holderegger, R., Gielly, L., et al. 541 (2012). Broad-scale adaptive genetic variation in alpine plants is driven by temperature and 542 precipitation. Molecular Ecology 21(15), 3729-3738. https://doi.org/10.1111/j.1365-

$543 \quad \underline{294 X .2012 .05656 . x}$

544 Mantel, N. (1967). The detection of disease clustering and a generalized regression approach. Cancer 545 Res. 27, 209-220.

546 Marrot, P., Garant, D., and Charmantier, A. (2017). Multiple extreme climatic events strengthen selection for earlier breeding in a wild passerine. Philosophical Transactions of the Royal Society B:

548 Biological Sciences 372(1723), 20160372. https://doi.org/10.1098/rstb.2016.0372

549 McRae, B. H. (2006). Isolation by resistance. Evolution 60(8), 1551-1561.

550 https://doi.org/10.1111/j.0014-3820.2006.tb00500.x

551 McRae, B. H., Dickson, B. G., Keitt, T. H., and Shah, V. B. (2008). Using circuit theory to model

552

553 connectivity in ecology, evolution, and conservation. Ecology 89(10), 2712-2724. https://doi.org/10.1890/07-1861.1

554 Meirmans, P. G. (2012). The trouble with isolation by distance. Molecular Ecology 21(12), 2839555 2846. https://doi.org/10.1111/j.1365-294X.2012.05578.x

556 Meirmans, P. G., and Van Tienderen, P. H. (2004). genotype and genodive: Two programs for the analysis of genetic diversity of asexual organisms. Molecular Ecology Notes 4(4), 792-794.

558 https://doi.org/10.1111/j.1471-8286.2004.00770.x

559 Morente-López, J., García, C., Lara-Romero, C., García-Fernández, A., Draper, D., and Iriondo, J.

560 M. (2018). Geography and Environment Shape Landscape Genetics of Mediterranean Alpine Species

561 Silene ciliata Poiret. (Caryophyllaceae). Frontiers in Plant Science 9, 1698.

562 https://doi.org/10.3389/fpls.2018.01698

563 Münzbergová, Z., Hadincová, V., Skálová, H., and Vandvik, V. (2017). Genetic differentiation and 564 plasticity interact along temperature and precipitation gradients to determine plant performance under 565 climate change. Journal of Ecology 105(5), 1358-1373. https://doi.org/10.1111/1365-2745.12762

566 Oksanen, J., Blanchet, F. G., Kindt, R., Legendre, P., Minchin, R. B., et al. (2018). vegan:

567 Community Ecology Package. R package version 2.5-3. https://CRAN.R-project.org/package=vegan. 

population genetic differentiation in the wild: Isolation by dispersal limitation, isolation by adaptation and isolation by colonization. Molecular Ecology 22(24), 5983-5999.

571 https://doi.org/10.1111/mec. 12561

572 Peakall, R., and Smouse, P. E. (2012). GenAlEx 6.5: Genetic analysis in Excel. Population genetic software for teaching and research--an update. Bioinformatics 28(19), 2537-2539. https://doi.org/10.1093/bioinformatics/bts460

Peng, S.-L., You, W.-H., Qi, G., and Yang, F.-L. (2013). Nitrogen and Phosphorus Uptake Capacity and Resource Use of Aquatic Vegetables Floating Bed in the Eutrophicated Lake. 2013 Third International Conference on Intelligent System Design and Engineering Applications 994-997. https://doi.org/10.1109/ISDEA.2012.237

Pritchard, J. K., Stephens, M., and Donnelly, P. (2000). Inference of population structure using

581 Pykälä, J. (2019). Habitat loss and deterioration explain the disappearance of populations of 582 threatened vascular plants, bryophytes and lichens in a hemiboreal landscape. Global Ecology and 583 Conservation 18, e00610. https://doi.org/10.1016/j.gecco.2019.e00610

584 Qin, B. (2008). Lake Taihu, China: Dynamics and environmental change. Dordrecht: Springer.

585 Quan, Z., Pan, L., Ke, W., Liu, Y., and Ding, Y. (2009). Sixteen polymorphic microsatellite markers 586 from Zizania latifolia Turcz. (Poaceae). Molecular Ecology Resources 9(3), 887-889.

587 https://doi.org/10.1111/j.1755-0998.2008.02357.x diversity of wild populations for ex situ conservation: Texas wild rice (Zizania texana) as a model. Genetic Resources and Crop Evolution 54(4), 837-848. https://doi.org/10.1007/s10722-006-9167-4

591 Rosenberg, N. A. (2003). distruct: A program for the graphical display of population structure.

592 Molecular Ecology Notes 4(1), 137-138. https://doi.org/10.1046/j.1471-8286.2003.00566.x

593 Rousset, F. (1997). Genetic Differentiation and Estimation of Gene Flow from F-Statistics Under 594 Isolation by Distance. Genetics 145(4), 1219.

595 Rousset, F., and Ferdy, J.-B. (2014). Testing environmental and genetic effects in the presence of

596 spatial autocorrelation. Ecography 37(8), 781-790. https://doi.org/10.1111/ecog.00566

597 Santamaría, L. (2002). Why are most aquatic plants widely distributed? Dispersal, clonal growth and 598 small-scale heterogeneity in a stressful environment. Acta Oecologica 23(3), 137-154.

599 https://doi.org/10.1016/S1146-609X(02)01146-3

600 Schneider, S., Roessli, D., and Excoffier, L. (2000). Arlequin: A Software for Population Genetics 601 Data Analysis, Version 2.0. Geneva, Switzerland: Genetics and Biometry Laboratory, Department of 602 Anthropology, University of Geneva. 
603 Segelbacher, G., Cushman, S. A., Epperson, B. K., Fortin, M.-J., Francois, O., Hardy, O. J., et al. 604 (2010). Applications of landscape genetics in conservation biology: Concepts and challenges.

605 Conservation Genetics 11(2), 375-385. https://doi.org/10.1007/s10592-009-0044-5

606 Sexton, J. P., Hangartner, S. B., and Hoffmann, A. A. (2014). Genetic isolation by environment or

607 distance: which pattern of gene flow is most common?: special section. Evolution 68(1), 1-15.

608 https://doi.org/10.1111/evo.12258

609 Shafer, A. B. A., and Wolf, J. B. W. (2013). Widespread evidence for incipient ecological speciation:

610 A meta-analysis of isolation-by-ecology. Ecology Letters 16(7), 940-950.

611 https://doi.org/10.1111/ele.12120

612 Shen, W., Song, C., Chen, J., Fu, Y., Wu, J., and Jiang, S. (2011). Transgenic Rice Plants Harboring 613 Genomic DNA from Zizania latifolia Confer Bacterial Blight Resistance. In Rice Science 18(1), 17614 22. https://doi.org/10.1016/S1672-6308(11)60003-6.

615 Slatkin, M. (1985). Gene flow in natural populations. Annu. Rev. Ecol. Syst. 16, 393-430.

616 Slatkin, M., and Barton, N. H. (1989). A comparison of three indirect methods for estimating average 617 levels of gene flow. Evolution 43(7), 1349-1368. https://doi.org/10.1111/j.1558-

$618 \quad \underline{5646.1989 . t b 02587 . x}$

619 Sork, V. L., Nason, J., Campbell, D. R., and Fernandez, J. F. (1999). Landscape approaches to 620 historical and contemporary gene flow in plants. Trends in Ecology \& Evolution 14(6), $219-224$.

621 https://doi.org/10.1016/S0169-5347(98)01585-7

$622 \mathrm{Su}, \mathrm{H}$. , Qu, L.-J., He, K., Zhang, Z., Wang, J., Chen, Z., and Gu, H. (2003). The Great Wall of China: 623 A physical barrier to gene flow? Heredity 90(3), 212-219. https://doi.org/10.1038/sj.hdy.6800237

624 Šurinová, M., Hadincová, V., Vandvik, V., and Münzbergová, Z. (2019). Temperature and 625 precipitation, but not geographic distance, explain genetic relatedness among populations in the 626 perennial grass Festuca rubra. Journal of Plant Ecology 12(4), 730-741.

627 https://doi.org/10.1093/jpe/rtz010

628 Tucker, J. M., Schwartz, M. K., Truex, R. L., Wisely, S. M., and Allendorf, F. W. (2014). Sampling 629 affects the detection of genetic subdivision and conservation implications for fisher in the Sierra 630 Nevada. Conservation Genetics 15(1), 123-136. https://doi.org/10.1007/s10592-013-0525-4

631 van Etten, J. (2017). R package gdistance: Distances and routes on geographical grids. Journal of 632 Statistical Software 76(13), 1-21. doi:10.18637/jss.v076.i13.

633 Van Oosterhout, C., Hutchinson, W. F., Wills, D. P. M., and Shipley, P. (2004). micro-checker: 634 Software for identifying and correcting genotyping errors in microsatellite data. Molecular Ecology 635 Notes 4(3), 535-538. https://doi.org/10.1111/j.1471-8286.2004.00684.X

636 van Strien, M. J., Holderegger, R., and Van Heck, H. J. (2015). Isolation-by-distance in landscapes: 637 Considerations for landscape genetics. Heredity 114(1), 27-37. https://doi.org/10.1038/hdy.2014.62 
638 Verity, R., and Nichols, R. A. (2016). Estimating the Number of Subpopulations (K) in Structured

639 Populations. Genetics 203(4), 1827-1839. https://doi.org/10.1534/genetics.115.180992.

640 Wagutu, G. K., Njeri, H. K., Fan, X. R., and Chen, Y. Y. (2020). Development and transferability of 641 SSR primers in the wild rice Zizania latifolia (Poaceae). Plant Science Journal 38(1), In Press.

642 Wang, H. M., Wu, G. L., Jiang, S. L., Huang, Q. N., Feng, B. H., Hunag, C. G., et al. (2015). Genetic 643 diversity of Zizania latifolia Griseb. from Poyang lake basin based on SSR and ISSR analysis.

644 Journal of Plant Genetic Resources 16(1), 133-141.

645 Wang, I. J., and Bradburd, G. S. (2014). Isolation by environment. Molecular Ecology 23(23), 5649646 5662. https://doi.org/10.1111/mec.12938

647 Wang, M. X., Zhang, H. L., Zhang, D. L., Qi, Y. W., Fan, Z. L., Li, D. Y., et al. (2008). Genetic 648 structure of Oryza rufipogon Griff. In China. Heredity 101(6), 527-535.

649 https://doi.org/10.1038/hdy.2008.61

650 Wang, T., Wang, Z., Xia, F., and Su, Y. (2016). Local adaptation to temperature and precipitation in 651 naturally fragmented populations of Cephalotaxus oliveri, an endangered conifer endemic to China.

652 Scientific Reports 6(1), 25031.https://doi.org/10.1038/srep25031

653 Wang, Y., Huang, L., and Fan, L. (2013). Main agronomic traits, domestication and breeding of Gu 654 (Zizania latifolia). Journal of Zhejiang University (Agriculture and Life Sciences) 39(6) 629-

655 635. DOI: ISSN: 1008-9209 CN: 33-1247/S.

656 Wang, Z., Wu, J., Madden, M., and Mao, D. (2012). China's Wetlands: Conservation Plans and 657 Policy Impacts. AMBIO 41(7), 782-786. https://doi.org/10.1007/s13280-012-0280-7

658 Wright, S. (1943). Isolation by distance. Genetics 28 (2), 114-138.

659 Wright, S. (1969). Evolution and the genetics of populations: The theory of gene frequencies. The 660 University of Chicago Press, Chicago, Illinois.

661 Wu. S., Yang, Q., and Zheng, D. (2003). Comparative study on eco-geographic regional systems 662 between China and USA. Acta Geographica Sinica 58(5), 686-694.

663 Wu, Z., Xu, X., Zhang, J., Wiegleb, G., and Hou, H. (2019). Influence of environmental factors on 664 the genetic variation of the aquatic macrophyte Ranunculus subrigidus on the Qinghai-Tibetan 665 Plateau. BMC Evolutionary Biology 19(1), 228. https://doi.org/10.1186/s12862-019-1559-0

666 Xu, X. W., Wu, J. W., Qi, M. X., Lu, Q. X., Lee, P. F., Lutz, S., et al. (2015). Comparative 667 phylogeography of the wild-rice genus Zizania (Poaceae) in eastern Asia and North America. Am J 668 Bot. 102(2):239-47. doi: 10.3732/ajb.1400323.

669 Xu, X., Ke, W., Yu, X., Wen, J., and Ge, S. (2008). A preliminary study on population genetic 670 structure and phylogeography of the wild and cultivated Zizania latifolia (Poaceae) based on Adh1a 671 sequences. Theoretical and Applied Genetics 116(6), 835-843. https://doi.org/10.1007/s00122-008$672 \underline{0717-3}$ 
673 Xu, X., Walters, C., Antolin, M. F., Alexander, M. L., Lutz, S., Ge, S., et al. (2010). Phylogeny and

674 biogeography of the eastern Asian-North American disjunct wild-rice genus (Zizania L.,

675 Poaceae). Molecular Phylogenetics \& Evolution 55(3), 1008-1017.

676 doi:10.1016/j.ympev.2009.11.018.

$677 \mathrm{Xu}, \mathrm{Z}$., and Zhou, G. (2017). Identification and Control of Common Weeds. Dordrecht: Springer

678 Netherlands.

679 Yu, C., Likun, L., Xiuyun, L., Wanli, G., and Bao, L. (2006). Isolation and characterization of a set 680 of disease resistance-gene analogs (RGAs) from wild rice, Zizania latifolia Griseb. I. Introgression, 681 copy number lability, sequence change, and DNA methylation alteration in several rice-Zizania 682 introgression lines. Genome 49(2), 150-158. doi:10.1139/G05-097.

683 Zhao, Y., Song, Z., Zhong, L., Li, Q., Chen, J., and Rong, J. (2019). Inferring the Origin of 684 Cultivated Zizania latifolia, an Aquatic Vegetable of a Plant-Fungus Complex in the Yangtze River 685 Basin. Frontiers in Plant Science 10, 1406.https://doi.org/10.3389/fpls.2019.01406

686 Zhao, Y., Vrieling, K., Liao, H., Xiao, M., Zhu, Y., Rong, J., et al. (2013). Are habitat fragmentation, 687 local adaptation and isolation-by-distance driving population divergence in wild rice Oryza

688 rufipogon? Molecular Ecology 22(22), 5531-5547. https://doi.org/10.1111/mec.12517

689 Zhao, Y., Zhong, L., Zhou, K., Song, Z., Chen, J., and Rong, J. (2018). Seed characteristic variations 690 and genetic structure of wild Zizania latifolia along a latitudinal gradient in China: Implications for 691 neo-domestication as a grain crop. AoB PLANTS 10(6). https://doi.org/10.1093/aobpla/ply072

692 Zhou, S., Wang, C., Yang, H., Wang, G., Wang, Y., and Li, J. (2007). Growth of Zizania latifolia and 693 Acorus calamus in sewage and their effect on sewage purification. Chin. J. App. Environ. Biol. 13, 694 454e457 (in Chinese with English abstract).

\section{Tables}

696 Table 1. Geographical information and summary measures of clonal diversity and genetic variation 697 for each of the 28 wild populations of Zizania latifolia along the five latitudinal regions starting from 698 the north towards the south.

\begin{tabular}{llcccccccc}
\hline Population & \multicolumn{1}{c}{ Location } & Regions & $\boldsymbol{N}$ & $\boldsymbol{G}$ & $\boldsymbol{N}_{\mathbf{a}}$ & $\boldsymbol{N}_{\mathbf{e}}$ & $\boldsymbol{H}_{\mathbf{O}}$ & $\boldsymbol{H}_{\mathbf{E}}$ & $\boldsymbol{F}_{\mathbf{I S}}$ \\
\hline BS & Baihilazi, Heilongjiang Province & & 22 & 21 & 1.880 & 1.509 & 0.303 & 0.261 & $-0.135^{* *}$ \\
XXT & Xiaoxintun, Heilongjiang Province & & 21 & 21 & 1.560 & 1.398 & 0.219 & 0.183 & $-0.172^{* *}$ \\
HDY & Hadayan, Heilongjiang Province & & 20 & 16 & 1.400 & 1.202 & 0.113 & 0.111 & 0.021 \\
KEB & Kuerbin River, Heilongjiang Province & $\mathrm{I}$ & 22 & 19 & 1.480 & 1.223 & 0.149 & 0.138 & -0.057 \\
LQQ & Lanqitun, Heilongjiang Province & & 20 & 19 & 1.920 & 1.549 & 0.282 & 0.297 & 0.077 \\
HW & Hongwei, Heilongiiang Province & & 20 & 19 & 1.920 & 1.684 & 0.278 & 0.286 & 0.055 \\
YLZ & Yihaoyuliangzi, Heilongjiang Province & 20 & 18 & 1.920 & 1.514 & 0.178 & 0.190 & 0.091 \\
\hline JH & Jinhua, Liaoning Province & & 20 & 20 & 2.160 & 1.627 & 0.292 & 0.280 & -0.017 \\
HR & Huanren, Liaoning Province & & 20 & 17 & 1.640 & 1.386 & 0.198 & 0.175 & -0.100 \\
ZD & Zhangdang, Liaoning Province & $\mathrm{II}$ & 20 & 20 & 1.560 & 1.358 & 0.204 & 0.175 & $-0.138^{* *}$ \\
DG & Donggang, Liaoning Province & & 20 & 20 & 1.800 & 1.361 & 0.234 & 0.193 & $-0.186^{* * *}$ \\
LZX & Liaozhong, Liaoning Province & & 20 & 20 & 3.320 & 2.262 & 0.448 & 0.434 & -0.007 \\
\hline
\end{tabular}




\begin{tabular}{|c|c|c|c|c|c|c|c|c|c|}
\hline HXD & Huanxiangdian, Shandong Province & & 20 & 20 & 2.040 & 1.548 & 0.316 & 0.288 & -0.071 \\
\hline DP & Dongpinghu, Shandong Province & & 20 & 20 & 3.120 & 2.188 & 0.470 & 0.436 & -0.053 \\
\hline LQ & Luqiao, Shandong Province & III & 20 & 20 & 3.200 & 2.169 & 0.442 & 0.436 & 0.012 \\
\hline MK & Mankou, Shandong Province & & 20 & 20 & 3.200 & 2.104 & 0.440 & 0.428 & -0.003 \\
\hline $\mathrm{CH}$ & Changhu Lake, Hubei Province & & 21 & 21 & 4.000 & 2.874 & 0.488 & 0.484 & 0.016 \\
\hline DT & Dongting Lake, Hunan Province & & 21 & 21 & 3.480 & 2.468 & 0.450 & 0.475 & $0.077 * *$ \\
\hline $\mathrm{HH}$ & Honghu Lake, Hubei Province & & 20 & 20 & 3.600 & 2.498 & 0.470 & 0.464 & 0.012 \\
\hline $\mathrm{LZ}$ & Liangzi Lake, Hubei Province & IV & 21 & 21 & 3.320 & 2.296 & 0.451 & 0.456 & 0.034 \\
\hline LG & Longgan Lake, Hubei Province & & 21 & 21 & 1.560 & 1.275 & 0.200 & 0.160 & $-0.224 * * *$ \\
\hline SJ & Shengjin Lake, Anhui Province & & 21 & 21 & 3.600 & 2.394 & 0.430 & 0.468 & $0.104 * * *$ \\
\hline $\mathrm{BD}$ & Baidang Lake, Anhui Province & & 22 & 22 & 3.280 & 2.169 & 0.476 & 0.458 & -0.017 \\
\hline NM & Nama, Guangxi Province & & 21 & 19 & 1.600 & 1.302 & 0.173 & 0.165 & -0.020 \\
\hline $\mathrm{FC}$ & Fangchenggang, Guangxi Province & & 21 & 21 & 1.600 & 1.405 & 0.236 & 0.205 & $-0.130 *$ \\
\hline $\mathrm{BL}$ & Beiliu City, Guangxi Province & $\mathrm{V}$ & 23 & 22 & 1.560 & 1.294 & 0.175 & 0.150 & $-0.138 * *$ \\
\hline WC & Wuchuan City, Guangdong Province & & 21 & 21 & 1.800 & 1.459 & 0.223 & 0.216 & -0.008 \\
\hline $\mathrm{DC}$ & Dongcheng, Guangdong Province & & 20 & 20 & 1.640 & 1.292 & 0.166 & 0.157 & -0.029 \\
\hline Mean & & & 20.643 & 20.000 & 2.327 & 1.743 & 0.304 & 0.292 & -0.036 \\
\hline
\end{tabular}

699 Note: $N$, number of individual plants; $N_{\mathrm{a}}$, observed alleles number; $N_{\mathrm{e}}$, effective allele number; $H_{\mathrm{o}}$, observed

700 heterozygosity; $H_{\mathrm{E}}$, expected heterozygosity; $F_{\mathrm{IS}}$, inbreeding coefficient; ${ }^{*} P<0.05 ;{ }^{* *} P<0.01 ;{ }^{* * *} P<0.001$.

701

702 Table 2. Genetic diversity found at 25 microsatellite loci in Zizania latifolia

\begin{tabular}{lcccccc}
\hline Locus & $A$ & $H_{\mathrm{O}}$ & $H_{\mathrm{E}}$ & $F_{\mathrm{ST}}$ & $F_{\mathrm{IS}}$ & $N m$ \\
\hline ZM4 & 7 & 0.278 & 0.304 & 0.602 & 0.111 & 0.060 \\
ZM25 & 6 & 0.192 & 0.183 & 0.762 & -0.022 & 0.045 \\
ZM26 & 9 & 0.281 & 0.278 & 0.641 & 0.016 & 0.058 \\
ZM28 & 4 & 0.114 & 0.114 & 0.818 & 0.026 & 0.037 \\
ZM35 & 12 & 0.459 & 0.463 & 0.451 & 0.034 & 0.062 \\
ZM44 & 11 & 0.495 & 0.510 & 0.386 & 0.050 & 0.059 \\
RM14233 & 12 & 0.379 & 0.339 & 0.599 & -0.090 & 0.060 \\
RM20118 & 6 & 0.410 & 0.342 & 0.556 & -0.170 & 0.062 \\
RM28090 & 7 & 0.529 & 0.435 & 0.431 & -0.197 & 0.061 \\
Zt1 & 7 & 0.290 & 0.250 & 0.692 & -0.130 & 0.053 \\
Zt23 & 6 & 0.187 & 0.187 & 0.718 & 0.027 & 0.051 \\
ZL1 & 30 & 0.706 & 0.607 & 0.292 & -0.136 & 0.052 \\
ZL3 & 29 & 0.413 & 0.480 & 0.476 & 0.167 & 0.062 \\
ZL4 & 28 & 0.396 & 0.444 & 0.512 & 0.131 & 0.062 \\
ZL5 & 28 & 0.416 & 0.454 & 0.511 & 0.108 & 0.062 \\
ZL9 & 5 & 0.211 & 0.212 & 0.560 & 0.095 & 0.062 \\
ZL10 & 7 & 0.276 & 0.277 & 0.510 & 0.028 & 0.062 \\
ZL31 & 7 & 0.346 & 0.305 & 0.427 & -0.109 & 0.061 \\
ZL32 & 8 & 0.315 & 0.291 & 0.482 & -0.056 & 0.062 \\
ZL36 & 5 & 0.213 & 0.193 & 0.739 & -0.085 & 0.048 \\
ZL42 & 5 & 0.105 & 0.110 & 0.445 & 0.079 & 0.062 \\
ZL43 & 4 & 0.117 & 0.115 & 0.432 & 0.014 & 0.061 \\
ZL55 & 4 & 0.072 & 0.072 & 0.875 & 0.016 & 0.027 \\
ZL56 & 5 & 0.344 & 0.273 & 0.649 & -0.236 & 0.057 \\
ZL57 & 4 & 0.067 & 0.059 & 0.908 & -0.125 & 0.021 \\
\hline Mean & 10.240 & 0.304 & 0.292 & 0.579 & -0.016 & 0.061 \\
\hline
\end{tabular}

703 Note: $A$, average number of alleles per locus; $H_{\mathrm{E}}$, expected heterozygosity; $H_{\mathrm{O}}$, observed heterozygosity; $F_{\mathrm{ST}}$, coefficient 704 of genetic differentiation; $\mathrm{Nm}$, gene flow

705 Table 3. AMOVA design and results (average over 25 loci) 


\begin{tabular}{|c|c|c|c|c|c|c|}
\hline Source of variation & d. f. & $\begin{array}{l}\text { Sum of } \\
\text { squares }\end{array}$ & Variance components & $\begin{array}{c}\text { Percentage } \\
\text { variation }\end{array}$ & Statistics & $P$ \\
\hline & & & Among population & & & \\
\hline Among populations & 27 & 5718.302 & 5.20096 & 57.88 & & $<0.001$ \\
\hline \multirow[t]{2}{*}{ Within populations } & 1092 & 133.310 & 3.78508 & 42.12 & $\emptyset_{\mathrm{pt}}=0.5787$ & $<0.001$ \\
\hline & & & Among clusters & & & \\
\hline Among clusters & 4 & 391.365 & 3.50502 & 36.44 & & $<0.001$ \\
\hline Within clusters & 23 & 2226.957 & 2.32734 & 24.20 & $\emptyset_{\mathrm{pt}}=0.6064$ & $<0.001$ \\
\hline
\end{tabular}

Table 4. Reciprocal causal modeling, partial and simple Mantel results for IBD, IBR and IBE

\begin{tabular}{lllll}
\hline & IBD & IBR & IBE \\
\cline { 2 - 5 } & Geo & Res & Env
\end{tabular}

I: Reciprocal causal modeling matrix

$\begin{array}{lllll}\text { IBD } & \text { Geo } & 0 & 0.0851 & \mathbf{0 . 4 9 6 1} \\ \text { IBR } & \text { Res } & -0.0851 & 0 & \mathbf{0 . 0 3 9 2} \\ \text { IBE } & \text { Env } & \mathbf{- 0 . 4 9 6 1} & \mathbf{- 0 . 0 3 9 2} & \mathbf{0}\end{array}$

II: Simple and Partial Mantel correlation matrix

$\begin{array}{lllll}\text { IBD } & \text { Geo } & 0.5830^{* * *} & 0.2684^{* * *} & 0.3063^{* * *} \\ \text { IBR } & \text { Res } & 0.1833^{* *} & 0.6051^{* * *} & 0.2724 * * * \\ \text { IBE } & \text { Env } & -0.1898 & 0.2332^{* * *} & 0.6160^{* * *}\end{array}$

709 Note: IBD, isolation by distance; IBR, isolation by resistance; IBE, isolation by environment; Geo, geographic distance;

710 Res, resistance distance; Env, environmental distance.

711 (I) Reciprocal causal modeling matrix; columns indicate test model and rows indicate alternative models. Each value 712 represents the relative support of the test model

713 (II) Simple and Partial Mantel correlation matrix. Columns indicates test model and rows indicate partialed-out models.

714 Values are r values for correlations, diagonal values are the simple Mantel test $\mathrm{r}$ of a variable. ${ }^{*} P<0.05 ;{ }^{* *} P<0.01 ;{ }^{* * *} P$

$715<0.001$.

716

717 Table 5. Generalized linear model for the influence of environmental variables on genetic diversity 718 measures. Values are significant at $P$-values $\leq 0.05$

\begin{tabular}{cccc}
\hline Independent variables & \multicolumn{3}{c}{ Dependent variables } \\
\hline bio_4 & $H_{\mathrm{E}}$ & $H_{\mathrm{O}}$ & $N_{\mathrm{a}}$ \\
\cline { 2 - 4 } bio_5 & - & - & 0.012 \\
bio_10 & $\mathbf{0 . 0 2 4}$ & $\mathbf{0 . 0 1 7}$ & - \\
bio_14 & - & 0.046 & 0.030 \\
bio_15 & - & - & 0.032 \\
bio_17 & $\mathbf{0 . 0 3 2}$ & - & $\mathbf{0 . 0 0 9 0}$ \\
bio_19 & - & - & 0.020 \\
\hline
\end{tabular}



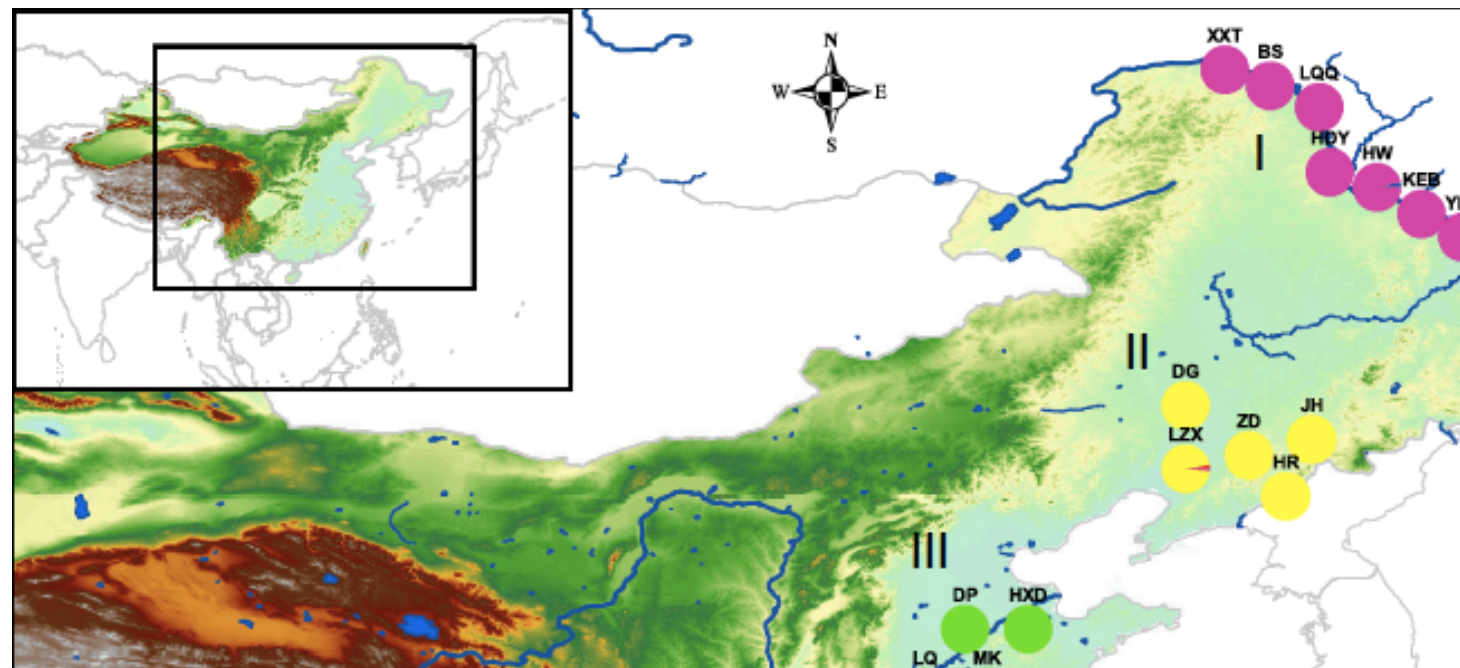

$\mathrm{ZD}$
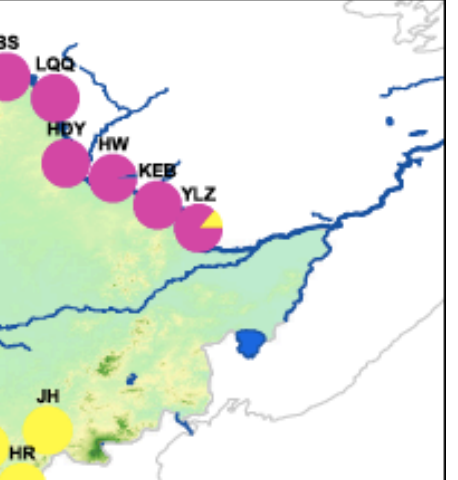

Figure 1: Geographical distribution of wild rice samples across the five (I to V) latitudinal regions in 

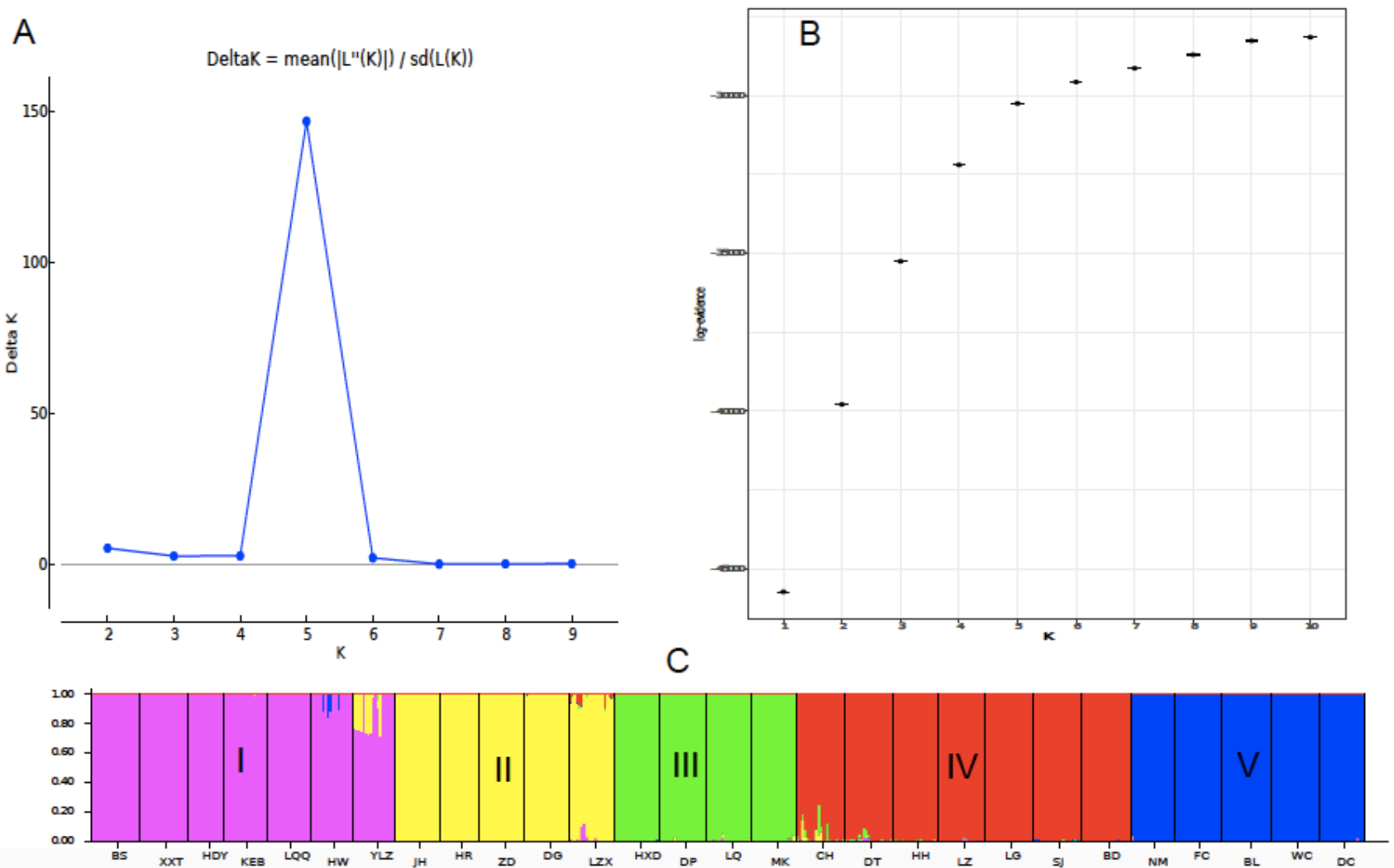

Figure 2: Bayesian analysis of population structure (STRUCTURE) for $K=5$ inferred by DISTRUCT as calculated by: (A), Evanno's delta $K$ and; (B), log-evidence in thermodynamic integration. (C) STRUCTURE composition of individuals, with each of the clusters corresponding to 

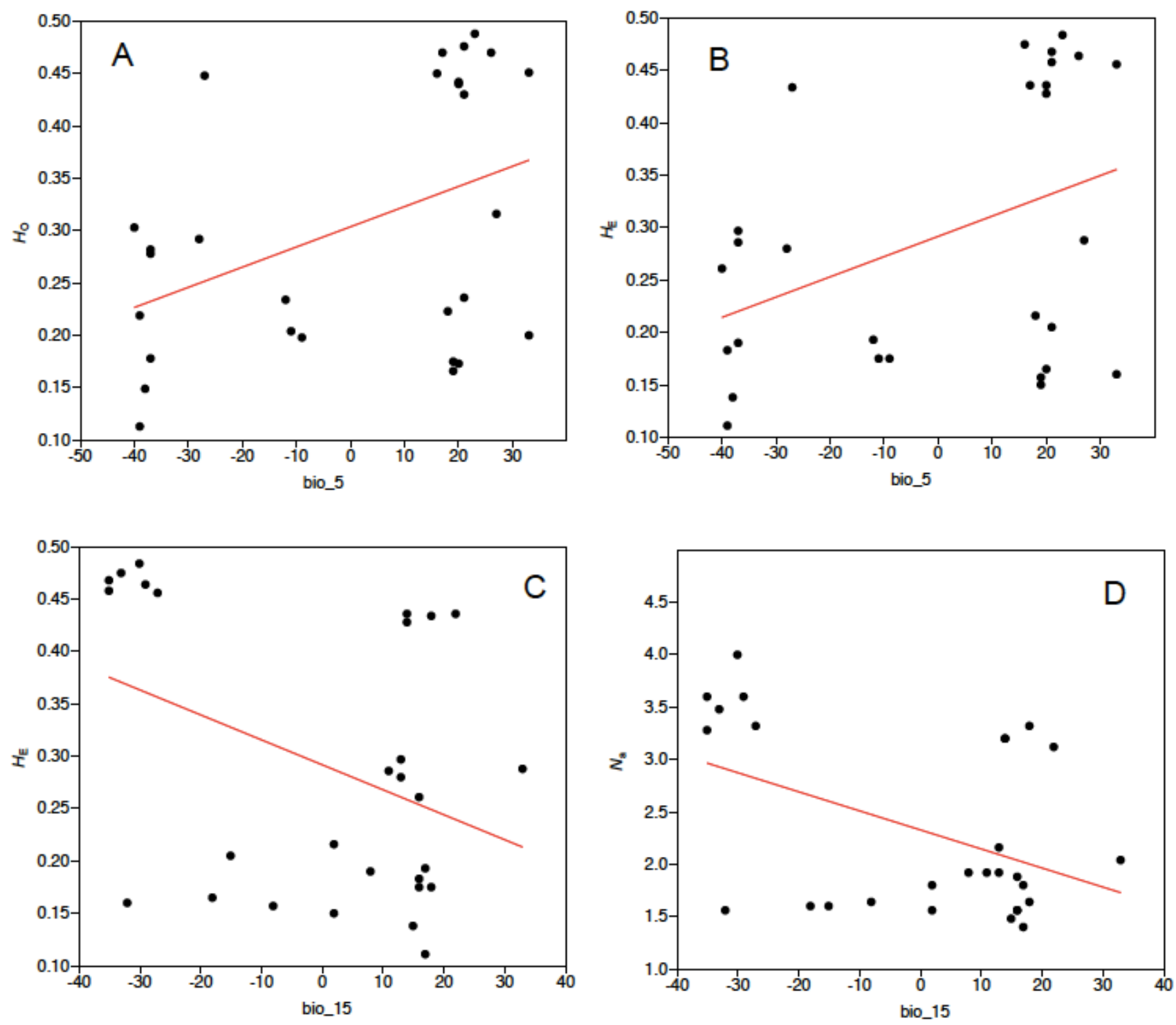

736 Figure 3: Significant relationships between genetic diversity estimators and the two most important environmental variables, based on variance inflation factor analysis. (A) $H_{\mathrm{O}}$, observed

738 heterozygosity; (B and C) $H_{\mathrm{E}}$, expected heterozygosity; (D) $N_{\mathrm{a}}$, number of alleles per population.

739 bio_5; Maximum temperature of warmest month, bio_15; precipitation seasonality. 